\title{
Effect of endotracheal tube leakage on respiratory function monitoring: Comparison of three neonatal ventilators
}

\author{
Ramadan A. Mahmoud ${ }^{\mathrm{a}, \mathrm{b}}$, Hans Proquitté ${ }^{\mathrm{a}}$, Somaya E. Hadhood ${ }^{\mathrm{b}}$ and Gerd Schmalisch ${ }^{\mathrm{a}, *}$ \\ ${ }^{a}$ Department of Neonatology, Charité University Medical Center, Berlin, Germany \\ ${ }^{\mathrm{b}}$ Department of Pediatrics, Sohag Faculty of Medicine, Sohag University, Sohag, Egypt
}

Received 7 December 2010

Revised 29 January 2011

Accepted 24 March 2011

\begin{abstract}
In preterm infants, lung function monitoring is important for lung-protective mechanical ventilation. In this study, we used a neonatal lung model to investigate the effect of endotracheal tube (ETT) leakage on the monitoring of tidal volume $\left(\mathrm{V}_{\mathrm{T}}\right)$ and lung mechanics using different ventilators. A neonatal lung model was ventilated via a $3 \mathrm{~mm}$ ETT using three ventilators, Babylog 8000, Leoni, and Stephanie. ETT leakage was simulated by open silicone tubes with different lengths. The volume delivered to the lung model was measured and compared with the displayed expiratory $\mathrm{V}_{\mathrm{T}}$ of the three ventilators. The effect of ETT leakage on lung mechanical parameters displayed by the ventilators was investigated for respiratory rates from $20 \mathrm{~min}^{-1}$ to $70 \mathrm{~min}^{-1}$ and a constant inspiratory time: expiratory time ratio of 1:1. The displayed ETT leakage depended on the size of the leak, ventilator settings, and the ventilator used. In the presence of ETT leakages, for all three ventilators, the displayed $\mathrm{V}_{\mathrm{T}}$ underestimated the true volume delivered to the lung. With increasing ETT leakage, displayed compliance was overestimated by Babylog 8000 and Stephanie, whereas Leoni underestimated compliance. The displayed resistance increased with increasing ETT leakage for the three ventilators, but quite different. The effect of ETT leakage on displayed $V_{T}$ and lung mechanical parameters is ventilator-dependent. ETT leakage can lead to incorrect measurements that indicate reduced $\mathrm{V}_{\mathrm{T}}$, improvement of lung compliance, or ETT obstruction.
\end{abstract}

Keywords: Endotracheal tube leakage, compliance; resistance, mechanical ventilation, monitoring, neonates

\section{Introduction}

Preterm infants have fragile lungs that are susceptible to injury during mechanical ventilation. The overall concepts of ventilator induced lung injury (VILI) are volu/barotrauma, injury related to over distension or stretching of the lung caused by excessive volume and pressure; atelectrauma, injury caused by alveolar collapse; and biotrauma, hyperactivity of inflammatory

*Corresponding author: Gerd Schmalisch PhD., Department of Neonatology, Charité University Medical Center, Charitéplatz 1, D-10117, Berlin, Germany. Tel.: + 4930450516 104; Fax: + 49 30450516 921; E-mail: gerd.schmalisch@charite.de. responses secondary to airway colonization and repeated lung decruitment and recruitment $[1,2]$. Several recent studies [3-5] have shown that optimizing the tidal volumes $\left(\mathrm{V}_{\mathrm{T}}\right)$ during mechanical ventilation is of benefit to the patient's lungs and consequently reduces VILI. Thus, careful monitoring of $\mathrm{V}_{\mathrm{T}}$ and lung mechanics is necessary during mechanical ventilation. In fact, this practice is standard in all modern neonatal ventilators, which provide continuous and real-time monitoring and allow for optimal $\mathrm{V}_{\mathrm{T}}[3,6,7]$.

In infants, uncuffed endotracheal tubes (ETT) are commonly used to protect airways and prevent subglottic stenosis [8]. Currently, there is no consensus regarding the quantification of ETT leakage, and 
different definitions of ETT leakage have been proposed [9]. Typically, ETT leakage is calculated as a percentage:

$$
\text { Leakage }(\%)=100 \frac{\mathrm{V}_{\mathrm{T} \text { insp }}-\mathrm{V}_{\mathrm{T} \exp }}{\mathrm{V}_{\mathrm{T} \text { insp }}}
$$

Where inspiratory tidal volume $\left(\mathrm{V}_{\mathrm{T}}\right.$ insp $)$ and expiratory tidal volume $\left(\mathrm{V}_{\mathrm{T} \text { exp }}\right)$ are the measured inspired and expired $\mathrm{V}_{\mathrm{T}}$, respectively $[10,11]$.

ETT leakage may affect ventilation if a portion of the inflating gas (intended for the lungs) escapes and leads to inadequate ventilation and errors in measurement of $\mathrm{V}_{\mathrm{T}}$ and lung mechanics [12]. The influence of ETT leakage on the measurement of $V_{T}$ [13-15] and lung mechanics $[11,16,17]$ in ventilated infants has been investigated previously. However, in all these studies, investigators used external signal processing, which is not available in most clinical settings. In a previous study [18], we have already investigated the effect of ETT leakage on the displayed $\mathrm{V}_{\mathrm{T}}$. The aim of the present study was to investigate the ventilatordepended effect of ETT leakage on lung mechanics parameters by use of a mechanical lung model.

\section{Materials and methods}

\subsection{Ventilators}

This study compared three neonatal ventilators: Baby$\log 8000^{\circledR}$ (Dräger Inc., Lübeck, Germany), Leoni ${ }^{\circledR}$ (Heinen \& Löwenstein, Bad Ems, Germany), and Stephanie $^{\circledR}$ (Stephan Medizintechnik GmbH, Gackenbach, Germany). All three ventilators were constant-flow, pressure-limited, and time-cycled devices that can be used for conventional mandatory ventilation, patient triggered ventilation, and continuous positive airway pressure in premature babies, neonates, and infants.

The three ventilators use different flow sensors between the Y-piece and the ETT and different signal evaluation. Babylog 8000 and Leoni use a hot-wire flow sensor with a very low resistance (Babylog 8000 flow sensor resistance not specified, dead space $0.9 \mathrm{~mL}$; Leoni flow sensor resistance $0.078 \mathrm{cmH}_{2} \mathrm{O} \cdot \mathrm{L}^{-1} \cdot \mathrm{s}^{-1}$, dead space $1 \mathrm{~mL}$ ). The Stephanie used a pneumotach as the flow sensor with a much higher resistance $\left(11 \mathrm{cmH}_{2} \mathrm{O} \cdot \mathrm{L}^{-1} \cdot \mathrm{s}^{-1}\right.$ at $5 \mathrm{~L} \cdot \mathrm{min}^{-1}$ flow $)$ and a dead space of $0.9 \mathrm{~mL}$ (all ventilators data from the manufacturers). There were also differences in displayed $\mathrm{V}_{\mathrm{T}}$ among the three devices. Babylog 8000 and Leoni displayed the $\mathrm{V}_{\mathrm{T}}$ exp, whereas Stephanie displayed $\mathrm{V}_{\mathrm{T}}$ insp and $\mathrm{V}_{\mathrm{T} \text { exp. }}$. In this comparative study, only $\mathrm{V}_{\mathrm{T} \text { exp }}$ was evaluated. All ventilators displayed ETT leakage in percent (as calculated by Equ. 1).

\subsection{Experimental set-up}

Figure 1 shows the experimental set-up used to study the effect of ETT leakage on lung function monitoring. The ventilators were used as in clinical practice, except that no humidifier was employed to prevent measurement errors due to water condensation. As shown in Figure 1, a custom-made neonatal lung model that consisted of two silicon bellows (Dräger Inc, Lübeck, Germany) was ventilated via a $3 \mathrm{~mm}$ ETT (Portex, Smiths Medical Watford, UK) that was $15 \mathrm{~cm}$ long. The pressure volume characteristic of the silicone bellows is shown in the bottom right of Figure 1. The static pressure volume curve was slightly non-linear, so that compliance depended on the pressure range used. For a given peak inspiratory pressure and positive end expiratory pressure (PEEP), the corresponding compliance was $1.3 \mathrm{~mL} \cdot \mathrm{cmH}_{2} \mathrm{O}^{-1}$. The resistance of the ETT increased linearly with flow, and can be calculated by the regression equation shown in the top right of Figure 1.

$\mathrm{V}_{\mathrm{T}}$ was measured by the ventilator at the Y-piece, and after the simulated ETT leakage by an additional pneumotach using a calibrated $\mathrm{CO}_{2} \mathrm{SMO}^{+}$monitor (Novametrix Medical Systems, Wallingford, CT). This allowed measurement of the actual volume delivered to the lung model (Fig. 1). The $\mathrm{CO}_{2} \mathrm{SMO}^{+}$used a low resistance pneumotach with a dead space was less than $0.5 \mathrm{~mL}$ and was calibrated with a $20 \mathrm{~mL}$ syringe.

\subsection{Simulation of ETT leakage}

ETT leakage was simulated by the use of four open silicone tubes (inner diameter $1.5 \mathrm{~mm}$ ) of variable length that were attached between the ETT and the lung model (Fig. 1). Table 1 shows the resistance of the silicon tubes, which was determined using a constant flow of $0.5 \mathrm{~L} \cdot \mathrm{min}^{-1}$ adjusted by a laboratory rotameter (Aalborg Instruments and Controls Inc., Orangeburg, USA). A digital manometer (Revue Thommen AG, Waldenburg, Switzerland) was used to measure the pressure drop across the tube. As expected, there was a strong linear relationship between tube length and measured tube resistance. 

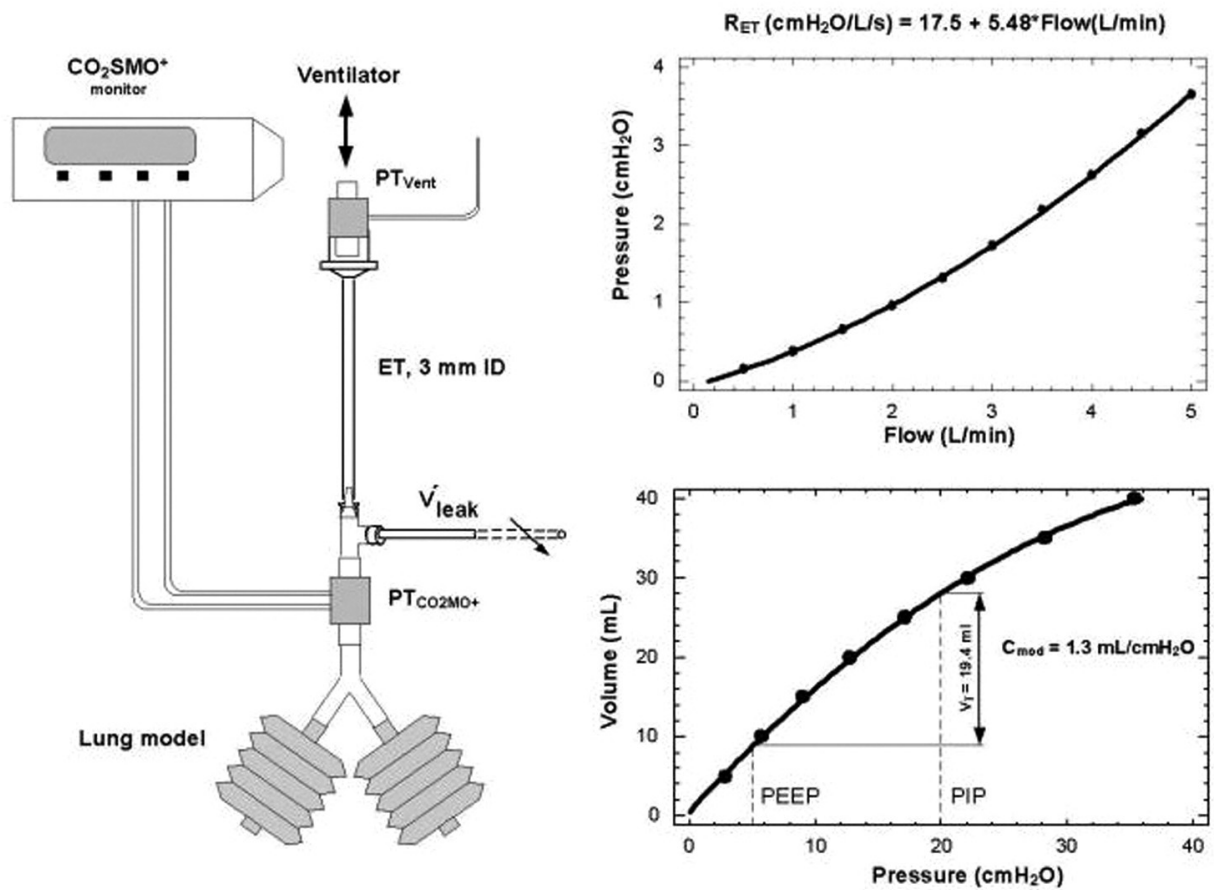

Fig. 1. Set-up of the lung model (left), pressure-volume characteristic of the lung model (right, bottom), and flow-pressure characteristics of the endotracheal tube (right, top). $\mathrm{PT}_{\text {vent }}=$ Ventilator flow sensor; $\mathrm{PT}_{\mathrm{CO} 2 \mathrm{SMO}+}=$ Pneumotach of $\mathrm{CO}_{2} \mathrm{SMO}^{+}$monitor; $\mathrm{V}^{\prime}$ leak $=\mathrm{Leak}$ flow; $\mathrm{R}_{\mathrm{ET}}=$ Resistance of the endotracheal tube; $\mathrm{C}_{\text {mod }}=$ Compliance of lung model; $\mathrm{ET}=$ Endotracheal tube; $\mathrm{PIP}=\mathrm{Peak}$ inspiratory pressure; $\mathrm{PEEP}=$ Positive end expiratory pressure.

Table 1

Means \pm SD of displayed endotracheal tube leakage of the three ventilators for the four simulated leaks, and their dependency on respiratory rate

\begin{tabular}{lccccc}
\hline Features & $\begin{array}{c}\text { Tube } \\
\text { length }(\mathrm{cm})\end{array}$ & $\begin{array}{c}\text { Tube resistance } \\
\left(\mathrm{cmH} \mathrm{CH}_{2} \mathrm{O} \cdot \mathrm{L}^{-1} \mathrm{~s}^{-1}\right)\end{array}$ & & \multicolumn{2}{c}{$\begin{array}{c}\text { Displayed endotracheal tube leakage in \% } \\
\left.\text { (respiratory rate: } 20 \mathrm{~min}^{-1} \text { to }^{70} \mathrm{~min}^{-1}\right)\end{array}$} \\
\cline { 3 - 6 } & & & Babylog 8000 & Leoni & Stephanie \\
\hline Leak 1 & 343 & 5205 & $20.2 \pm 2.5-3.2 \pm 1.7$ & $21.6 \pm 1.1-1.0 \pm 2.2$ & $8.2 \pm 0.4-2.4 \pm 0.1$ \\
Leak 2 & 172 & 2460 & $42.2 \pm 1.9-14.4 \pm 1.7$ & $38.4 \pm 0.9-12.6 \pm 0.5$ & $15.4 \pm 0.5-4.3 \pm 0.1$ \\
Leak 3 & 95 & 1503 & $56.8 \pm 0.8-22.2 \pm 0.8$ & $55.2 \pm 0.4-23.8 \pm 0.8$ & $22.8 \pm 0.4-6.6 \pm 0.2$ \\
\hline
\end{tabular}

\subsection{Protocol of in-vitro measurements}

This study was performed in the Infant Lung Function Laboratory of the Charité and all flow sensors were calibrated before each study according to the manufacturers' instructions.

For each ventilator, measurements were started in Intermittent Positive Pressure Ventilation mode without leakage, with the respiratory rate $(\mathrm{RR})$ of the ventilator varied from $20 \mathrm{~min}^{-1}$ to $70 \mathrm{~min}^{-1}$ and all other parameters kept constant (flow: $6 \mathrm{~L} \cdot \mathrm{min}^{-1}$; Peak inspiratory pressure: $20 \mathrm{cmH}_{2} \mathrm{O}$; PEEP: $5 \mathrm{cmH}_{2} \mathrm{O}$, inspiratory time: expiratory time (I:E) 1:1). Then, tubes of decreasing length were attached and RR was varied in the same way. Each series of leakage measurements was repeated five times. Before each series of measurements, we waited 30 min before measurements were recorded. After a parameter change, we waited at least 5 min before new values were recorded.

All measured data are presented as means with SDs. The coefficients of variation $(\mathrm{CV}[\%]=100 \times$ $\mathrm{SD} /$ mean) of all measured parameters were calculated from five repetitions, to describe the reproducibility of the measurements. 


\section{Results}

\subsection{ETT Leakage measurements}

For all three ventilators, displayed leakage increased with decreasing RR and increasing leak size (Table 1). The I:E ratio was kept constant in all measurements. There was no statistically significant difference between Babylog 8000 and Leoni, but ETT leakages displayed by Stephanie were about half of those displayed by the other ventilators. Within each ventilator, the ETT leakage measurements were highly reproducible with a median (range) coefficients of variation (CVs) of $1.75 \%(0$ to $9.8 \%$ ) for Babylog 8000, 0.7\% (0 to $9.2 \%$ ) for Leoni, and $0.04 \%$ (0 to $6.2 \%$ ) for Stephanie.

\section{2. $V_{T}$ measurements}

In the presence of ETT leakage, Tidal volume displayed by the ventilator $\left(\mathrm{V}_{\mathrm{T} \text { vent }}\right)$ decreased with increasing ETT leakage nearly independently of RR for all three ventilators (Fig. 2). For the highest simulated leakage (Leak 4), the volume error was $21 \%$ (0.7) for Babylog
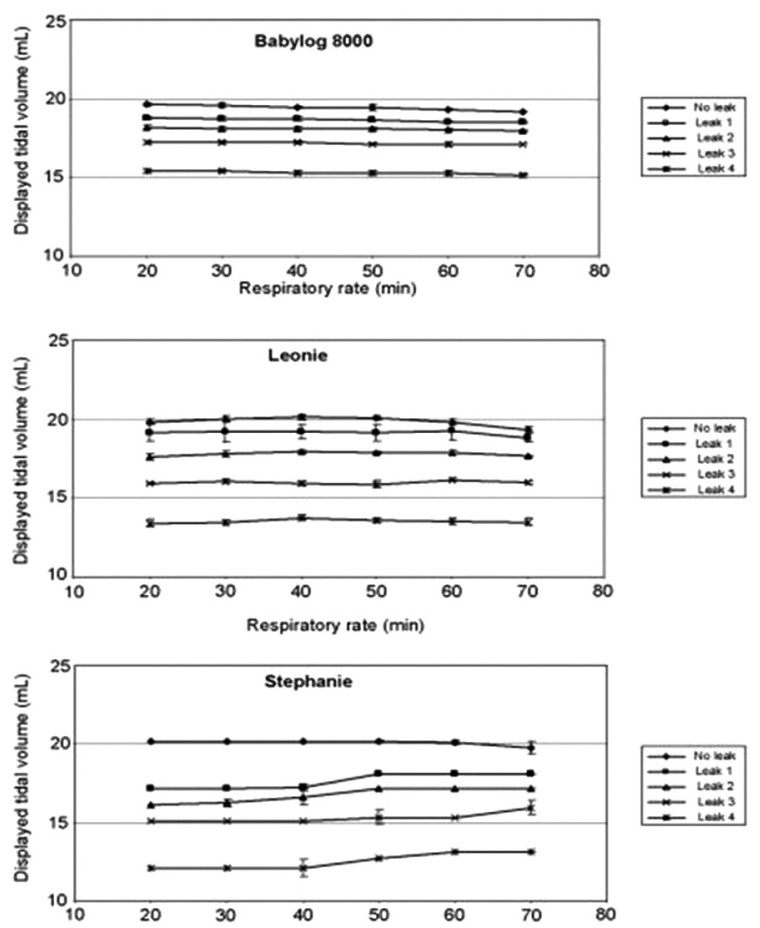

Fig. 2. Displayed tidal volume measured by the three ventilators in relation to respiratory rate for the four simulated endotracheal tube leakages.
$8000,30 \%$ (1.1) for Leoni, and 33\% (3.3) for Stephanie. In contrast to $\mathrm{V}_{\mathrm{T} \text { vent }}$, the volume delivered to the lung $\left(\mathrm{V}_{\mathrm{T} \text { Lung }}\right)$ was nearly independent of the simulated ETT leakage and RR (Fig. 3). $\mathrm{V}_{\mathrm{T}}$ Lung decreased by about $0.4 \%$ for Babylog 8000, 2\% for Leoni, and 5.6\% for Stephanie.

The reproducibility of the volume measurements was better than that of the ETT leakage. All CVs were $<1.1 \%$ for Babylog 8000, $<3.5 \%$ for Leoni, and $<4.3 \%$ for Stephanie.

\subsection{Compliance measurements}

The static compliance of the lung model was $1.3 \mathrm{~mL} \cdot \mathrm{cmH}_{2} \mathrm{O}^{-1}$. In the absence of ETT leakage, the displayed compliance of all ventilators was in the RR range $\left(20 \mathrm{~min}^{-1}\right.$ to $70 \mathrm{~min}^{-1}$ ) nearly independent of RR (Fig. 4).
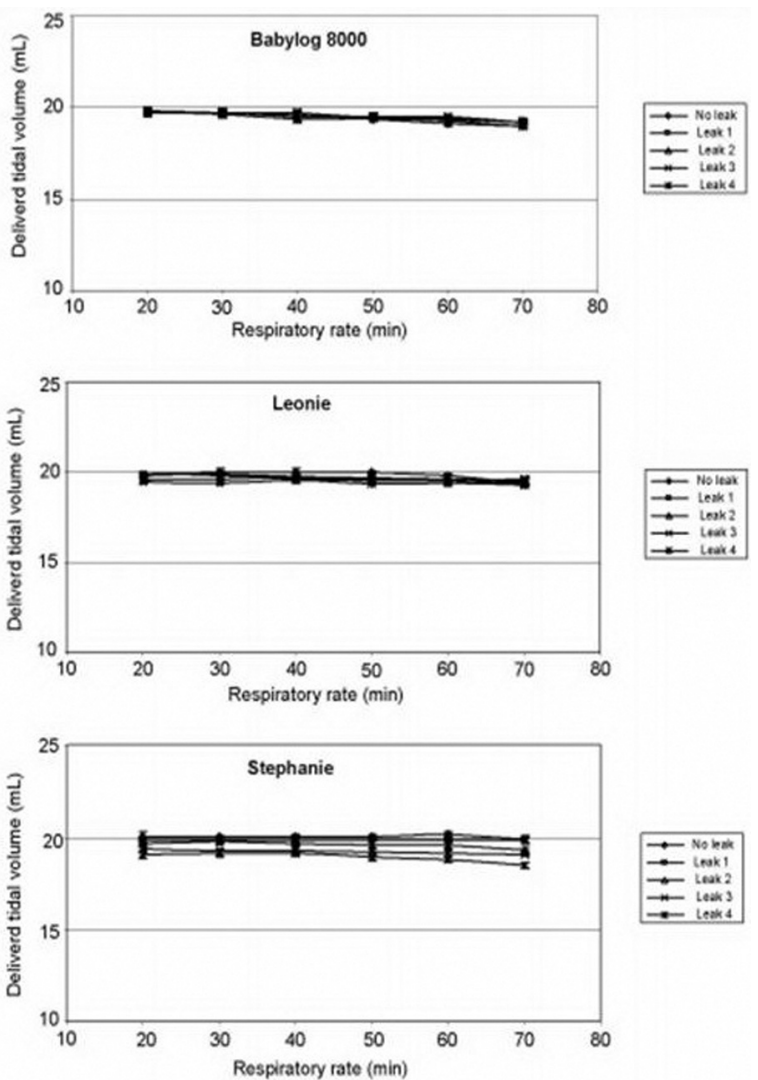

Fig. 3. Delivered tidal volume in the lung measured by $\mathrm{CO}_{2} \mathrm{SMO}^{+}$ monitor in relation to respiratory rate for the four simulated endotracheal tube leakages of the three ventilators. 

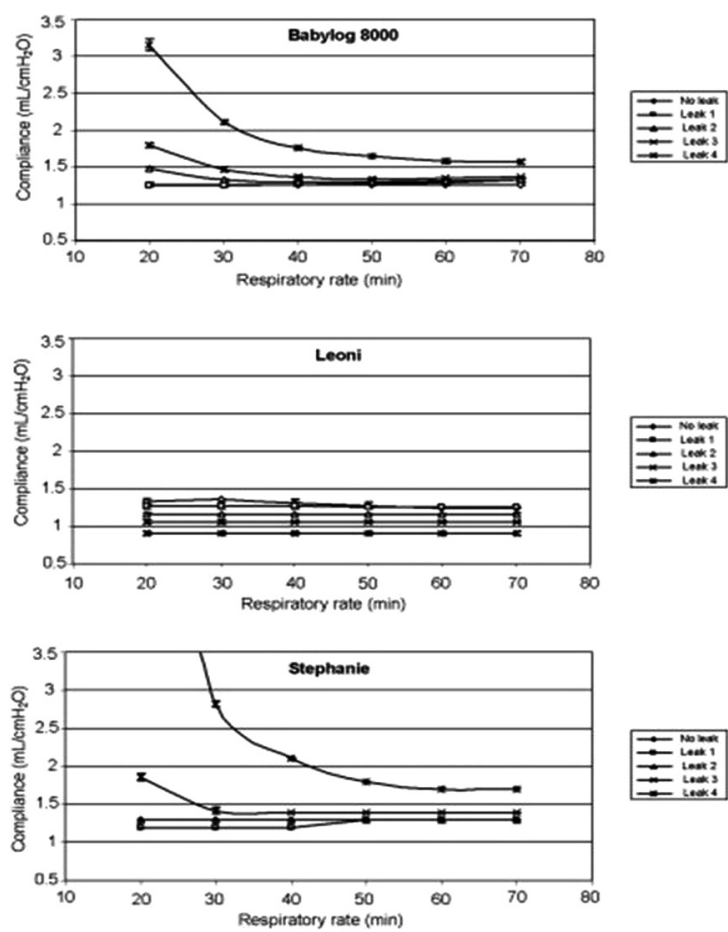

Fig. 4. Measured compliance of the three ventilators in relation to respiratory rate for the four simulated endotracheal tube leakages.

The effect of ETT leakage on displayed compliance was very different among the three ventilators (Fig. 4). For Babylog 8000 and Stephanie, displayed compliance was overestimated with increasing ETT leakage. For Leoni, measured compliance was underestimated with greater ETT leakage.

For a small ETT leakage, the dependency of displayed compliance on RR was negligible (Fig. 4). However, as ETT leakage increased, there was an increased dependence on RR for Babylog 8000 and Stephanie, with the measured compliance increasing with decreasing RR in both ventilators (Fig. 4). In contrast, Leoni showed no dependence of compliance measurement on RR, even for high ETT leakage (Fig. 4).

The reproducibility of the serial compliance measurements was also very high. The median (range) of the CVs was $1.08 \%(0.41 \%-2.71 \%)$ for Babylog $800,0 \%$ $(0 \%-4.86 \%)$ for Leoni, and $0 \%(0 \%-3.1 \%)$ for Stephanie.

\subsection{Resistance measurements}

Compared to the measurement of compliance, the measurement of resistance was more difficult because
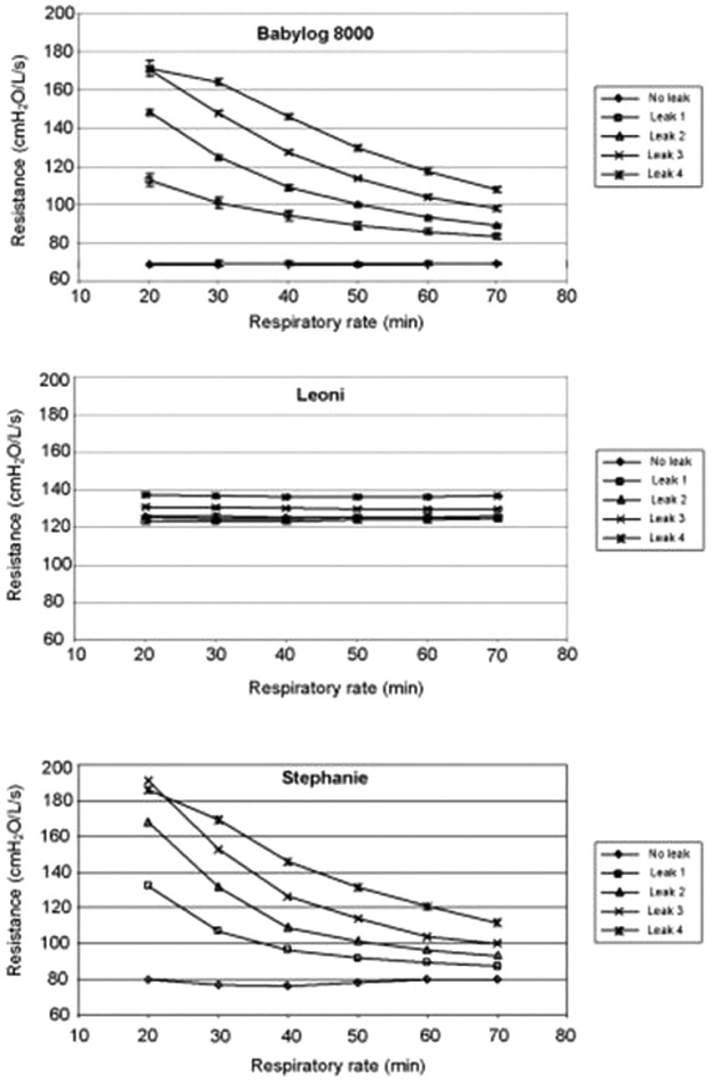

Fig. 5. Measured resistance of the three ventilators in relation to respiratory rate for the four simulated endotracheal tube leakages.

the resistance of the ETT tube is flow-dependent, and no fixed value for model resistance can be given. However, if the measuring conditions are the same, all ventilators should display the same resistance. Despite our use of comparable measurement conditions, there were distinct differences in the measured resistance of the three ventilators, even in the absence of ETT leakage (Fig. 5). In the absence of ETT leakage, the effect of RR on measured resistance was negligible for all three ventilators.

Also in contrast to the compliance, the effect of ETT leakage and RR on displayed respiratory resistance was distinctly higher, and there were distinct differences among the ventilators (Fig. 5). In all three ventilators, as ETT leakage increased, displayed resistance increased. However, for Babylog 8000 and Stephanie, resistance increased with decreasing RR; for Leoni, the effect of RR on displayed resistance was negligible.

The reproducibility of the serial resistance measurements was similar to the reproducibility of the compliance measurements. The median (range) of the CVs of all the 
resistance measurements of the three ventilators were $1.2 \%(0.58 \%-2.97 \%)$ for Babylog 8000, 0.6\% (0.12\%$1.63 \%)$ for Leoni and $0.9 \%(0 \%-3.68 \%)$ for Stephanie.

\section{Discussion}

In this study of three neonatal ventilators, we demonstrated that for a constant I:E ratio the displayed ETT leakage depended significantly on RR for all leakage simulations. In addition, we found significant differences in the displayed leakage among the three ventilators, likely due to the use of different leakage algorithms by different manufacturers. An ETT leakage led to an underestimation of $\mathrm{V}_{\mathrm{T}}$ delivered to the lung in all three ventilators, but the effect on lung mechanics was quite different among the ventilators in their dependence on RR. As RR becomes lower, the leakage-dependent error in the lung mechanic parameters becomes higher.

The ventilator-dependency of the effect of ETT leakage on respiratory function monitoring hampers the comparability between different ventilators. This clearly has important clinical implications that should be considered in multicenter studies when different ventilators are used.

\subsection{ETT leakage}

Unfortunately, ventilator manufacturers do not typically provide detailed descriptions of the algorithms used to calculate displayed ETT leakage, and the use of different algorithms can lead to discordant results (Table 1). Furthermore, the measurement of air leakage is typically defined as "the difference between inspired and expired volumes", and this is susceptible to technical [19] and physiological disturbances [20]. This may explain our findings of higher CVs in ETT leakage measurements than in $\mathrm{V}_{\mathrm{T}}$ measurements. If the I:E ratio is not changed the displayed ETT leakage dependent on RR, so that any change in RR will lead to change in the displayed ETT leakage, without any real change in leak size. The dependence of the ETT leakage on ventilator settings, the size of the leak and the respiratory mechanics hampers the interpretation of any leakage data [17].

\section{2. $V_{T}$}

In the presence of ETT leakage, displayed $\mathrm{V}_{\mathrm{T}}$ vent underestimated the true volume delivered to the lung for all three ventilators, even though the volume delivered to the lung was nearly constant. The constancy of $\mathrm{V}_{\mathrm{T}}$ lung may be explained by a low-pressure drop across the ETT, because resistance of the leak tubes was distinctly higher than the expiratory resistance of the ventilator. Only the Stephanie ventilator indicated a small (about 5.6\%) decrease in $\mathrm{V}_{\mathrm{T}}$ lung, with the increased leakage likely attributable to higher expiratory resistance (higher resistance of the pneumotach compared to anemometric flow sensors).

Leak-dependent errors of the displayed volume could have significant clinical consequences. For example, if pressure is adjusted to attain a target $\mathrm{V}_{\mathrm{T}}$ based on an underestimated $\mathrm{V}_{\mathrm{T}}$ in the presence of large ETT leakage, this may lead to lung over-inflation. Furthermore, volume monitoring and airflow measurements are the basis for volume-targeted ventilation as volume guarantee mode, when ventilator pressures are adapted to display $\mathrm{V}_{\mathrm{T}}$ vent. Keszler and Abubakar [21] stated that volume-targeted ventilation modes failed in the presence of substantial ETT leakage ( $>40 \%$ ).

Several previous studies have proposed leak-correction algorithms to correct for leakage-dependent volume errors that arise from pressure and flow signals $[13,15,17]$. In a lung model, Herber-Jonat et al. [13] found that volume correction was possible for ETT leakages up to $90 \%$. Furthermore, they described a separate determination of inspiratory and expiratory ETT leakage and developed an algorithm to correct $\mathrm{V}_{\mathrm{T}}$ insp and $\mathrm{V}_{\mathrm{T} \text { exp }}$ in the presence of ETT leakage. However, in routine clinical practice, external signal processing is not available, and most ventilators only display total ETT leakage in percentages, making the separate correction of $\mathrm{V}_{\mathrm{T}}$ insp and $\mathrm{V}_{\mathrm{T}}$ exp impossible.

\subsection{Compliance and resistance}

Our results indicate that ETT leakage had a much stronger effect on measured lung mechanics than on measured $\mathrm{V}_{\mathrm{T}}$. In addition to depending on the accuracy of the flow and pressure measurements [22], measured respiratory compliance and resistance also depend on the phase shift between the pressure and flow waveforms [23], and on the correct identification of the beginning and end of the breathing cycle [24]. ETT leakage affects the magnitude of the flow and volume signal as well as the phase shift between measured signals. This makes assessment of the effect of ETT leakage on measured mechanical parameters of the lung much more difficult [25]. 
Furthermore, in contrast to the measurement of $\mathrm{V}_{\mathrm{T}}$, several methods (e.g. calculation during inspiration, during expiration, or during the whole breathing cycle) can be used to calculate lung mechanical parameters with different results [26]. In neonatal ventilators, the most common method uses the linear resistance-compliance model, with determination of model parameters by least squares analysis [27]. However, the instruction manuals of most ventilators do not provide details of the methods used. Babylog 8000 uses a linear regression analysis, but Leoni and Stephanie provide no details of their methodologies.

The present study also showed that the relationship between ETT leakage and measuring errors of lung mechanics was highly dependent on the type of ventilator. Thus, we believe that some of the recommendations in the literature about the acceptance of lung mechanical measurements in the presence of ETT leakages should not be generalized. For example, Kondo et al. [16] suggested that these measurements would be reliable only if the expiratory portion of the breath was used, whereas Main et al. [17] found that measurement of lung mechanics was unreliable in the inspiratory and expiratory portion of the breath if ETT leakage was greater than $20 \%$. We suggest that such recommendations be considered with caution.

A leakage-dependent measuring error of lung mechanics could lead to incorrect clinical interpretations. Thus, Babylog 8000 and Stephanie overestimated the displayed compliance as ETT leakage increased, incorrectly indicating an improvement in lung mechanics. On the contrary, the Leoni ventilator underestimated the displayed compliance as ETT leakage increased, incorrectly indicating a deterioration of lung mechanics.

The measured resistance increased with increasing ETT leakage in all three ventilators. Thus, the presence of ETT leakage could lead to an incorrect conclusion that the respiratory airway or the ETT tube was obstructed. In clinical practice, the value of resistance monitoring is limited, because it is impacted by multiple factors, including airway diameter, respiratory muscle activity, gas flow, PEEP, and length and diameter of the ETT tube [28]. Therefore, resistance monitoring is only to be used to monitor the conductivity of the respiratory airway and the ETT tube.

Several algorithms have been suggested to reduce the effect of ETT leakage on the measurement of lung mechanics [10,13,29]. Nikischin et al. [10] developed an algorithm for correction of compliance in the presence of leakage up $80 \%$ and resistance up to a leakage of $55 \%$, even in the presence of non-linear pressure-volume relationships. Similar to volume correction, these numerical corrections are also based on knowledge of measured flow and pressure at the Y-piece during the ventilator cycle, which are not commonly available.

\subsection{Limitations of the study}

Our mechanical model has already been used, in a similar manner, in several leakage studies $[10,18,30]$. However, there are some limitations.

In this study of each ventilator only one exemplar with one flow sensor could be tested, and meanwhile newer versions of the tested ventilators became available in the markets, which may differ in their properties of the investigated ventilators. This limits the generalization of the results.

Furthermore, our laboratory setting differs from the clinical practice (e.g. by elimination of the humidifier, use of an unphysilogical I:E ratio of $1: 1$ and the neglect of pressure-dependent changes of the leak size). Condense water mainly in the leak tubes had significantly impaired the measurements by highly variable leak resistances. Because leakage-dependent measuring errors are highly dependent on the timing parameters of the breathing cycle, a constant I:E ratio of $1: 1$ was chosen to make the interpretation of the results easier.

An important limitation of our method is that we did not consider the superimposition of measured flow signals by spontaneous breathing, which may have seriously impaired calculation of $\mathrm{V}_{\mathrm{T}}$ and ETT leakage. However, we were able to simulate idealized conditions to investigate the relationship between ETT leakage and displayed $\mathrm{V}_{\mathrm{T}}$.

The measurement of lung mechanics in our model also has some limitations. The static compliance was slightly pressure-dependent and the measured compliance by the ventilator is a dynamic compliance, which may be comparable with the static compliance only for low frequencies. The interpretation of resistance due to flow-dependency was more difficult. However, we used the same model and identical ventilation settings to investigate all three ventilators, so our results provide a meaningful comparison of measured lung mechanical parameters, but not the calculation of measuring errors.

In conclusion, monitoring of volume and lung mechanics in ventilated neonates is important to minimize VILI. 
However, the $\mathrm{V}_{\mathrm{T}}$ and lung mechanics displayed by neonatal ventilators can be misleading when large ETT leakages are present. In particular, neonatal ventilators tend to underestimate $\mathrm{V}_{\mathrm{T}}$, falsely indicate improvement in respiratory compliance, and falsely indicate an increase of airway resistance. Furthermore, the use of different algorithms for the calculation of $\mathrm{V}_{\mathrm{T}}$, lung mechanics, and leakage hampers the comparison of ventilators. We suggest the use of standardized ETT leakage measurements in neonatal ventilators and the development of better algorithms for leakage correction. Moreover, as recommended by a task force of the European Respiratory Society and American Thoracic Society [31], there is an urgent need for manufacturers of neonatal ventilators to describe the details of the algorithms used to make volume corrections. Future clinical studies are necessary to investigate the extent to which ETT leakage impairs mechanical ventilation, and the role of this in the pathogenesis of VILI.

\section{Acknowledgments}

The authors thank Hendrik Fischer for technical support and Dr. Scott Butler of English Manager Science Editing, Sydney, Australia, for linguistic correction.

\section{References}

[1] Gupta S, Sinha SK, Donn SM. Ventilatory management and bronchopulmonary dysplasia in preterm infants. Semin Fetal Neonatal Med 2009;14(6):367-73.

[2] Aly H. Ventilation without tracheal intubation. Pediatrics 2009;124(2):786-9.

[3] Ventilation with lower tidal volumes as compared with traditional tidal volumes for acute lung injury and the acute respiratory distress syndrome. The Acute Respiratory Distress Syndrome Network. N Engl J Med 2000;342(18):1301-8.

[4] Carlo WA, Stark AR, Wright LL, Tyson JE, Papile LA, Shankaran S, et al. Minimal ventilation to prevent bronchopulmonary dysplasia in extremely-low-birth-weight infants. J Pediatr 2002;141(3):370-4.

[5] Meade MO, Cook DJ, Guyatt GH, Slutsky AS, Arabi YM, Cooper DJ, et al. Lung Open Ventilation Study Investigators. Ventilation strategy using low tidal volumes, recruitment maneuvers, and high positive end-expiratory pressure for acute lung injury and acute respiratory distress syndrome: a randomized controlled trial. JAMA 2008;299(6):637-45.

[6] Lista G, Colnaghi M, Castoldi F, Condò V, Reali R, Compagnoni $\mathrm{G}$, et al. Impact of targeted-volume ventilation on lung inflammatory response in preterm infants with respiratory distress syndrome (RDS). Pediatr Pulmonol 2004;37(6):510-4.

[7] Graziani LJ, Spitzer AR, Mitchell DG, Merton DA, Stanley C, Robinson N, et al. Mechanical ventilation in preterm infants: neurosonographic and developmental studies. Pediatrics 1992; 90(9):515-22.
[8] Mahmoud RA, Proquitté H, Fawzy N, Bührer C, Schmalisch G. Tracheal tube airleak in clinical practice and impact on tidal volume measurement in ventilated neonates. Pediatr Crit Care Med 2011;12(3):196-205.

[9] Schmalisch G, Fischer H, Roehr CC, Proquitté H. Comparison of different techniques to measure air leaks during CPAP treatment in neonates. Med Eng Phys 2009;31(1);124-30.

[10] Nikischin W, Lange M. Correction of compliance and resistance altered by endotracheal tube leaks and non-linear pressure/ volume-relationships. Eur. J. Appl. Physiol 2007;99(3):301-11.

[11] Kuo CY, Gerhardt T, Bolivar J, Claure N, Bancalari E. Effect of leak around the endotracheal tube on measurements of pulmonary compliance and resistance during mechanical ventilation: a lung model study. Pediatr Pulmonol 1996;22(1):35-43.

[12] Bernstein G, Knodel E, Heldt GP. Airway leak size in neonates and autocycling of three flow-triggered ventilators Crit Care Med 1995;23(10):1739-44.

[13] Herber-Jonat S, von Bismarck P, Freitag-Wolf S, Nikischin W. Limitation of measurements of expiratory tidal volume and expiratory compliance under conditions of endotracheal tube leaks. Pediatr Crit Care Med 2008;9(1):69-75.

[14] Al-Majed SI, Thompson JE, Watson KF, Randolph AG. Effect of lung compliance and endotracheal tube leakage on measurement of tidal volume. Crit Care 2004;8(6):R398-R402.

[15] Bijaoui E, Carry PY, Eberhard A, Andrini P, Perdrix JP, Baconnier P. Correction to the airflow measurement in the presence of a leak between the trachea and endotracheal tube. Can J Anaesth 1997;44(2):216-24 (in French).

[16] Kondo T, Matsumoto I, Lanteri CJ, Sly PD. Respiratory mechanics during mechanical ventilation: a model study on the effects of leak around a tracheal tube. Pediatr Pulmonol 1997;24(6):423-8.

[17] Main E, Castle R, Stocks J, James I, Hatch D. The influence of endotracheal tube leak on the assessment of respiratory function in ventilated children. Intensive Care Med 2001;27 (11):1788-97.

[18] Mahmoud RA, Fischer HS, Proquitté H, Shalaby HM, Schmalisch G. Relationship between endotracheal tube leakage and under-reading of tidal volume in neonatal ventilators. Acta Paediatr 2009;98(7):1116-22.

[19] Foitzik B, Schmalisch G, Wauer RR. Effect of physical properties of respiratory gas on pneumotachographic measurement of ventilation in newborn infants. Biomed Tech (Berl) 1994;39(4):85-92 (in German).

[20] Schmalisch G, Wauer RR, Foitzik B, Patzak A. Influence of preterm onset of inspiration on tidal breathing parameters in infants with and without CLD. Respir Physiol Neurobiol 2003;135(1):39-46.

[21] Keszler M, Abubakar KM. Volume guarantee ventilation. Clin Perinatol 2007;34(1):107-16, vii.

[22] Kreit JW, Sciurba FC. The accuracy of pneumotachograph measurements during mechanical ventilation. Am J Respir Crit Care Med 1996;154(4):913-7.

[23] Cappa P, Sciuto SA, Silvestri S. Experimental evaluation of errors in the measurement of respiratory parameters of the newborn performed by a continuous flow neonatal ventilator. J Med Eng Technol 2006;30(1):31-40.

[24] Schmidt M, Foitzik B, Wauer RR, Winkler F, Schmalisch G Comparative investigations of algorithms for the detection of breaths in newborns with disturbed respiratory signals. Comput Biomed Res 1998;31(6):413-25.

[25] Nikischin W, Lange M. Correction of compliance and resistance altered by endotracheal tube leaks. Pediatr Crit Care Med 2003;4(3):344-52. 
[26] Davis GM, Lands LC. Measurement of infant pulmonary mechanics: comparative analysis of techniques. Pediatr Pulmonol 1997;23(2):105-13.

[27] Lucangelo U, Bernabé F, Blanch L. Respiratory mechanics derived from signals in the ventilator circuit. Respir Care 2005;50:55-65.

[28] DiBlasi RM, Salyer JW, Zignego JC, Redding GJ, Richardson CP. The impact of imposed expiratory resistance in neonatal mechanical ventilation: a laboratory evaluation. Respir Care 2008;53(11):1450-60.
[29] Schulze A. Enhancement of mechanical ventilation of neonates by computer technology. Semin Perinatol 2000;24(6):429-44.

[30] Fischer HS, Roehr CC, Proquitté H, Wauer RR, Schmalisch G. Assessment of volume and leak measurements during CPAP using a neonatal lung model. Physiol Meas 2008;29(1):95-107.

[31] Frey U, Stocks J, Sly P, Bates J. Specification for signal processing and data handling used for infant pulmonary function testing. ERS/ATS Task Force on Standards for Infant Respiratory Function Testing. European Respiratory Society/ American Thoracic Society. Eur Respir J 2000;16(5):1016-22. 